\title{
Resposta de duas cultivares de arroz irrigado à densidade de semeadura e à adubação nitrogenada(1)
}

\author{
Carlos Henrique Paim Mariot( ${ }^{(2)}$, Paulo Regis Ferreira da Silva ${ }^{(3)}$, Valmir Gaedke Menezes ${ }^{(2)}$ \\ e Leandro Leonardo Teichmann ${ }^{(4)}$
}

\begin{abstract}
Resumo - Diversos estudos foram realizados sobre densidade de semeadura e adubação nitrogenada em arroz irrigado, mas poucos trabalhos estudaram esses dois fatores conjuntamente. O objetivo deste trabalho foi avaliar o efeito da densidade de semeadura e da adubação nitrogenada no rendimento de grãos e nos componentes do rendimento, em duas cultivares de arroz irrigado. O experimento foi realizado no campo, durante os anos agrícolas de 1998/1999 e 1999/2000. Os tratamentos constituíramse das combinações de duas cultivares de arroz irrigado (BR-IRGA 410 e IRGA 417), quatro densidades de semeadura $\left(50,100,150\right.$ e $\left.200 \mathrm{~kg} \mathrm{ha}^{-1}\right)$ e quatro níveis de nitrogênio $\left(0,40,80\right.$ e $\left.120 \mathrm{~kg} \mathrm{ha}^{-1}\right)$, distribuídos em blocos ao acaso, com quatro repetições. O rendimento de grãos em resposta à adubação nitrogenada não foi influenciado pela densidade de semeadura, exceto na densidade mais baixa, no segundo ano. O rendimento de grãos não variou dentro da faixa de densidade de semeadura testada. A eficiência de uso do nitrogênio foi maior na cultivar BR-IRGA 410 do que na IRGA 417 e diminuiu com o incremento da adubação nitrogenada.
\end{abstract}

Termos para indexação: Oryza sativa, característica agronômica, grão, componente de rendimento.

\section{Response of two flooded rice cultivars to seeding and nitrogen rates}

\begin{abstract}
Many studies about seeding and nitrogen rates in flooded rice were carried out, but few works have studied these two factors altogether. The objective of this study was to evaluate the effect of seeding and nitrogen rates on grain yield and its components, in two flooded rice cultivars. The experiment was carried out in field conditions during the 1998/1999 and 1999/2000 growing seasons. Treatments consisted of the combinations of two flooded rice cultivars (BR-IRGA 410 and IRGA 417), four seeding rates $\left(50,100,150\right.$, and $\left.200 \mathrm{~kg} \mathrm{ha}^{-1}\right)$ and four nitrogen rates $\left(0,40,80\right.$, and $\left.120 \mathrm{~kg} \mathrm{ha}^{-1}\right)$ in a randomized blocks design with four replications. Grain yield in response to nitrogen fertilizer was not influenced by seeding rate, except in the lowest density, in the second year. Grain yield did not vary within the range of seeding rate tested. Nitrogen use efficiency was higher in BR-IRGA 410 cultivar than in IRGA 417 and it decreased with increment in $\mathrm{N}$ fertilizer.
\end{abstract}

Index terms: Oryza sativa, agronomic characters, grain, yield components.

\section{Introdução}

O nitrogênio (N) é essencial para as plantas, porque faz parte das moléculas de clorofilas, citocromos

(1) Aceito para publicação em 15 de outubro de 2002.

Trabalho extraído da dissertação de mestrado apresentada pelo primeiro autor à Universidade Federal do Rio Grande do Sul (UFRGS), Porto Alegre, RS.

(2) Instituto Rio-Grandense do Arroz, Estação Experimental do Arroz, Setor de Fitotecnia, Caixa Postal 29 CEP 94930-030 Cachoeirinha, RS. E-mail: mariot_carlos@hotmail.com, irgafito@via-rs.net

(3) UFRGS, Dep. de Plantas de Lavoura, Caixa Postal 776, CEP 91501-970 Porto Alegre, RS. Bolsista do CNPq. E-mail: paulo.silva@vortex.ufrgs.br

(4) UFRGS. Bolsista da Fapergs. E-mail: saoborjars@uol.com.br e de todas as enzimas e coenzimas. Também participa na formação da panícula e dos grãos de arroz (Barbosa Filho, 1987), além de ser o elemento encontrado em maior quantidade nas plantas, depois do $\mathrm{H}$, $\mathrm{C}$ e $\mathrm{O}$, e ser constituinte de proteínas e ácidos nucléicos responsáveis pela transferência da informação genética (Arima, 1995). Como conseqüência, adubos nitrogenados são os mais utilizados no mundo (Raij, 1991).

Por sua alta mobilidade no solo, o $\mathrm{N}$ tem sido estudado intensamente com o propósito de maximizar a eficiência de seu uso. Para tanto, tem-se buscado reduzir sua perda no solo e melhorar sua absorção pelas plantas (Bredemeier \& Mundstock, 2000). Vários trabalhos revelaram a importância do $\mathrm{N}$ no incremento do rendimento de grãos, no aumento do nú- 
mero de afilhos e de panículas por unidade de área do arroz (Ghobrial, 1983; Lopes et al., 1996; Singh \& Pillai, 1996).

No arroz irrigado, a resposta à adubação nitrogenada é influenciada pelas variações na temperatura e na radiação solar incidentes durante as fases vegetativa e reprodutiva da cultura. Assim, em anos com maiores temperaturas e radiação solar, ou seja, com mais energia fotossintética, as respostas do rendimento de grãos à adubação nitrogenada são maiores (Barbosa Filho, 1987).

Diversos trabalhos realizados no Rio Grande do Sul mostraram que densidades de 100 a $200 \mathrm{~kg} \mathrm{ha}^{-1}$ de sementes aumentaram a população inicial de plantas e o número de colmos e de panículas por unidade de área em relação a densidades menores sem, todavia, resultarem em elevação do rendimento de grãos (Pedroso \& Reginatto, 1981; Infeld \& Zonta, 1984; Pedroso, 1987; Silva et al., 1995).

$\mathrm{O}$ incremento da densidade de semeadura reduz os números de afilhos por planta e de grãos formados por panícula. Esta compensação é a causa de não terem sido encontradas diferenças significativas no rendimento de grãos com aumento da densidade de semeadura dentro de uma determinada faixa de valores, quando as demais práticas culturais não foram limitantes (Ghobrial, 1983; Jones \& Snyder, 1987; Gravois \& Helms, 1992).

Alguns trabalhos realizados com arroz irrigado associando diferentes densidades de semeadura a níveis de adubação nitrogenada não revelaram interação significativa entre esses fatores em relação ao rendimento de grãos (Ghobrial, 1983; Reddy et al., 1986). No entanto, em densidades de semeadura mais baixas pode haver uma compensação no rendimento de grãos do arroz com aplicação de doses mais elevadas de $\mathrm{N}$, porque esse nutriente estimula o afilhamento de plantas de arroz e aumenta o número de panículas por unidade de área e o número de grãos formados por panícula (Ghobrial, 1983).

O objetivo deste trabalho foi avaliar o efeito da densidade de semeadura e da adubação nitrogenada no rendimento de grãos e nos componentes do rendimento, em duas cultivares de arroz irrigado.

\section{Material e Métodos}

O experimento foi realizado no campo, durante os anos agrícolas de 1998/1999 e 1999/2000, na Estação Experi- mental do Arroz (EEA), do Instituto Rio-Grandense do Arroz (IRGA), Município de Cachoeirinha, situado na região climática da depressão central do Estado do Rio Grande do Sul, a sete metros de altitude. As coordenadas geográficas são $29^{\circ} 55^{\prime} 30^{\prime \prime} \mathrm{S}$ e $50^{\circ} 58^{\prime} 21^{\prime \prime} \mathrm{O}$ e o clima da região é do tipo subtropical úmido, conforme classificação de Köppen (Brasil, 1973), considerado como de transição entre os tipos $\mathrm{Cfa}_{1}$ (isoterma anual inferior a $18^{\circ} \mathrm{C}$ ) e Cfa (isoterma anual superior a $18^{\circ} \mathrm{C}$ ) (Instituto de Pesquisa Agropecuária, 1979). O solo da área experimental é classificado como Gleissolo Háplico Ta distrófico típico (Embrapa, RJ, 1999), com $140 \mathrm{~g} \mathrm{~kg}^{-1}$ de argila e as seguintes características químicas $(0-20 \mathrm{~cm}): \mathrm{pH}$ (água), 4,7; $\mathrm{pH}$ (SMP), 6,5; MO, $150 \mathrm{~g} \mathrm{~kg}^{-1} ; \mathrm{P}, 9,8 \mathrm{mg} \mathrm{L}^{-1} ; \mathrm{K}^{+}$, $36 \mathrm{mg} \mathrm{L}{ }^{-1} ; \mathrm{Ca}^{2+}, 1,0 \mathrm{cmol}_{\mathrm{c}} \mathrm{L}^{-1} ; \mathrm{e} \mathrm{Mg}^{2+}, 0,3 \mathrm{cmol}_{\mathrm{c}} \mathrm{L}^{-1}$.

O delineamento experimental usado nos dois anos foi o de blocos ao acaso, em esquema fatorial com 32 tratamentos, constituídos pela combinação de duas cultivares de arroz irrigado, quatro densidades de semeadura e quatro níveis de $\mathrm{N}$, com quatro repetições. As cultivares BR-IRGA 410 e IRGA 417 são do tipo moderno de plantas, de baixa estatura e alta capacidade de afilhamento, com folhas curtas e eretas e grãos longo-finos, sendo a primeira de ciclo médio (125-130 dias da emergência à maturação plena) e a segunda, de ciclo precoce (110-115 dias) (Epagri, 1997). As densidades de semeadura foram $50,100,150 \mathrm{e}$ $200 \mathrm{~kg} \mathrm{ha}^{-1}$ de sementes aptas, correspondendo a aproximadamente $180,360,540$ e 720 sementes $\mathrm{m}^{-2}$, respectivamente. A adubação nitrogenada $\left(0,40,80\right.$ e $120 \mathrm{~kg} \mathrm{ha}^{-1}$ de $\mathrm{N}$ ) foi aplicada em cobertura, utilizando-se uréia ( $45 \%$ de N), parcelada em doses iguais. A primeira, aplicada aos 12 e aos 15 dias após emergência (DAE) (entre os estádios dois e três), respectivamente, no primeiro e segundo anos agrícolas e a segunda, aplicada aos 40 e aos 44 DAE (estádio três), respectivamente, no primeiro e segundo ano de realização da pesquisa.

O preparo do solo foi efetuado em área previamente sistematizada sob cultivo convencional, por meio de operações de lavração, gradagens e passagem de rolo destorroador. Aplicaram-se, entre as operações de

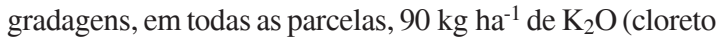
de potássio) e $60 \mathrm{~kg} \mathrm{ha}^{-1}$ de $\mathrm{P}_{2} \mathrm{O}_{5}$ (superfosfato triplo). A semeadura foi realizada em seis de novembro de $1998 \mathrm{e}$ em 22 de novembro de 1999, por semeadora de parcelas acoplada ao trator. As unidades experimentais eram constituídas de dez linhas espaçadas em $20 \mathrm{~cm}$ e suas áreas foram de $12,4 \mathrm{~m}^{2}$ e de $16 \mathrm{~m}^{2}$, respectivamente, no primeiro e segundo anos. As demais práticas culturais foram realizadas conforme Epagri (1997) e Embrapa RS (1999).

Os estádios de crescimento do arroz foram descritos conforme International Rice Research Institute (1996). 
A emergência das plântulas ocorreu 13 e 12 dias após a semeadura, respectivamente, nos anos agrícolas de 1998/ 1999 e 1999/2000. A diferenciação do primórdio da panícula ocorreu aos 57 (1998/1999) e 50 (1999/2000) dias após a emergência, na cultivar BR-IRGA 410, e aos 50 (1998/ 1999) e 46 (1999/2000) dias após a emergência, na cultivar IRGA 417. O florescimento ocorreu aos 82 (1998/1999) e 77 (1999/2000) dias após a emergência, na cultivar BR-IRGA 410 e aos 76 (1998/1999) e 70 (1999/2000) dias após a emergência, na cultivar IRGA 417. A maturação dos grãos ocorreu aos 125 (1998/1999) e 123 (1999/2000) dias após a emergência, na cultivar BR-IRGA 410 e aos 117 (1998/1999) e 115 (1999/2000) dias após a emergência, na cultivar IRGA 417.

As variáveis eficiência de uso do N (EUN) nos grãos, número de panículas por unidade de área, número de grãos formados por panícula, peso de 1.000 grãos e esterilidade de espiguetas foram obtidas a partir de uma mesma amostra colhida numa área de $0,30 \mathrm{~m}^{2}$ de cada parcela. Com exceção da EUN avaliada na parte aérea das plantas no florescimento (estádio seis) e nos grãos (estádio nove), todas as demais variáveis foram determinadas nos dois anos agrícolas.

A EUN foi calculada conforme Baligar et al. (1990). Na parte aérea das plantas (1) e nos grãos (2), a EUN foi determinada mediante as seguintes fórmulas:

$\mathrm{EUN}=\mathrm{RMS} \div$ QNAT, em que QNAT = TNT $\mathrm{x}$ MS (1)

$\mathrm{EUN}=\mathrm{RG} \div \mathrm{QNAG}$, em que $\mathrm{QNAG}=\mathrm{TNG} \times \mathrm{PG}$

onde: RMS é o rendimento de massa seca $\left(\mathrm{g} \mathrm{m}^{-2}\right)$; QNAT é a quantidade de $\mathrm{N}$ acumulado no tecido da planta $\left(\mathrm{g} \mathrm{g}^{-1}\right)$; TNT é o teor de $\mathrm{N}$ no tecido da planta (\%), determinado conforme Tedesco et al. (1995); MS é a massa seca por amostra (g), obtida pela pesagem da parte aérea das plantas secadas em estufa a $65^{\circ} \mathrm{C}$ até atingirem peso constante; RG é o rendimento de grãos $\left(\mathrm{g} \mathrm{m}^{-2}\right)$; QNAG é a quantidade de $\mathrm{N}$ acumulado nos grãos $\left(\mathrm{g} \mathrm{g}^{-1}\right)$; TNG é o teor de $\mathrm{N}$ nos grãos (\%), determinado conforme Tedesco et al. (1995) e PG é o peso de grãos por amostra (g), corrigido para $13 \%$ de umidade.

O rendimento de grãos foi obtido por meio de pesagem dos grãos, corrigidos para $13 \%$ de umidade, colhidos em $4,8 \mathrm{~m}^{2}$ e em $6,4 \mathrm{~m}^{2}$, respectivamente, no primeiro e segundo anos agrícolas. A cultivar IRGA 417 foi colhida em 18 de março de 1999 e em 29 de março de 2000 e a BR-IRGA 410, em 26 de março de 1999 e em seis de abril de 2000, após terem atingido a maturação plena de grãos (estádio nove).

As variáveis foram analisadas pelo teste $\mathrm{F}$ e os fatores quantitativos submetidos à análise de regressão, testandose os modelos linear e quadrático. Os coeficientes "b" das equações de regressão linear foram comparados pelo teste $t$.

\section{Resultados e Discussão}

O rendimento de grãos aumentou com o aumento do nível de $\mathrm{N}$, de modo linear e quadrático, respectivamente, nas cultivares IRGA 417 e BR-IRGA 410, e esta foi mais produtiva, no primeiro ano (Figura 1). No segundo ano, o rendimento de grãos aumentou linearmente com o aumento do nível de $\mathrm{N}$ somente na densidade de semeadura de $50 \mathrm{~kg} \mathrm{ha}^{-1}$, ou seja, para cada $10 \mathrm{~kg} \mathrm{ha}^{-1}$ de $\mathrm{N}$ aplicado, o rendimento aumentou $140 \mathrm{~kg} \mathrm{ha}^{-1}$ (Figura 2). A cultivar BR-IRGA 410 foi mais produtiva também no segundo ano, apresentando rendimento de grãos $\left(8,2 \mathrm{t} \mathrm{ha}^{-1}\right) \quad 15,5 \%$ maior do que a IRGA 417 (7,1 t ha-1). Não houve efeito da densidade de semeadura sobre o rendimento de grãos nos dois anos experimentais (Tabela 1).

Quanto ao número de panículas $\mathrm{m}^{-2}$, houve efeitos simples de densidade de semeadura e de cultivar no primeiro ano agrícola. A equação $\mathrm{y}=309,708+1,0975 \mathrm{x}\left(\mathrm{R}^{2}=0,97\right)$ descreve o aumento linear do número de panículas $\mathrm{m}^{-2}$ com o incremento da densidade de semeadura. A cultivar IRGA 417 e a BR-IRGA 410 produziram 463 e 431 panículas $\mathrm{m}^{-2}$,

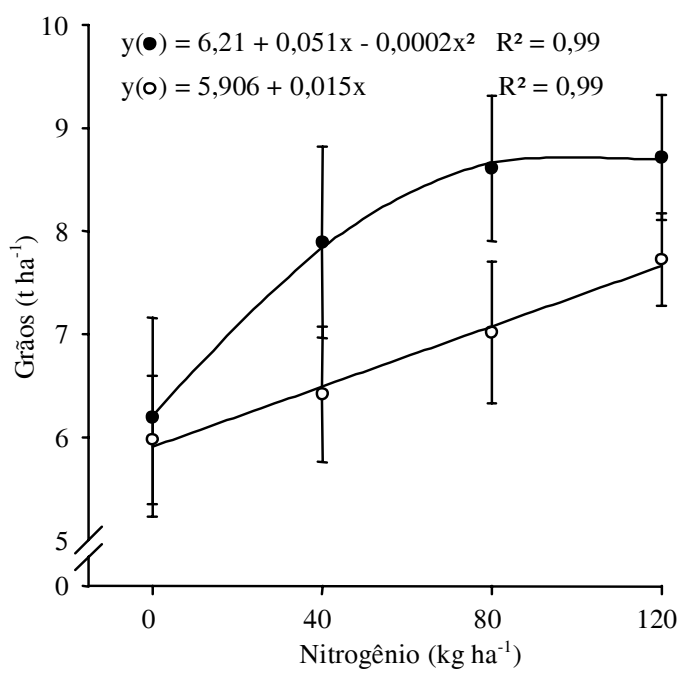

Figura 1. Rendimento de grãos de arroz irrigado, cultivares BR-IRGA 410 (○) e IRGA 417 (O) em razão do nível de nitrogênio aplicado, na média de quatro densidades de semeadura (50, 100, 150 e $\left.200 \mathrm{~kg} \mathrm{ha}^{-1}\right)$. Barra vertical em cada ponto representa o desvio-padrão da média. Cachoeirinha, RS, 1998/1999. 
respectivamente. Na estação de crescimento seguinte, foi significativa a interação tríplice entre densidade de semeadura, cultivar e nível de $\mathrm{N}$ para esta variável. Com incremento da densidade de semeadura, o número de panículas $\mathrm{m}^{-2}$ de ambas as cultivares aumentou linearmente em todos os níveis de $\mathrm{N}$, exceto no nível mais alto em relação à cultivar BR-IRGA 410, na qual a regressão não foi significativa. Estes aumentos lineares, para a cultivar BR-IRGA 410, são descritos pelas equações $y=336+1,065 x\left(R^{2}=0,90\right)$, $y=348,5+0,782 x\left(R^{2}=0,94\right)$ e $y=360,25+0,777 x$ $\left(\mathrm{R}^{2}=0,66\right)$, respectivamente, nos níveis de 0,40 e $80 \mathrm{~kg} \mathrm{ha}^{-1}$ de N. Com relação à IRGA 417, são descri-

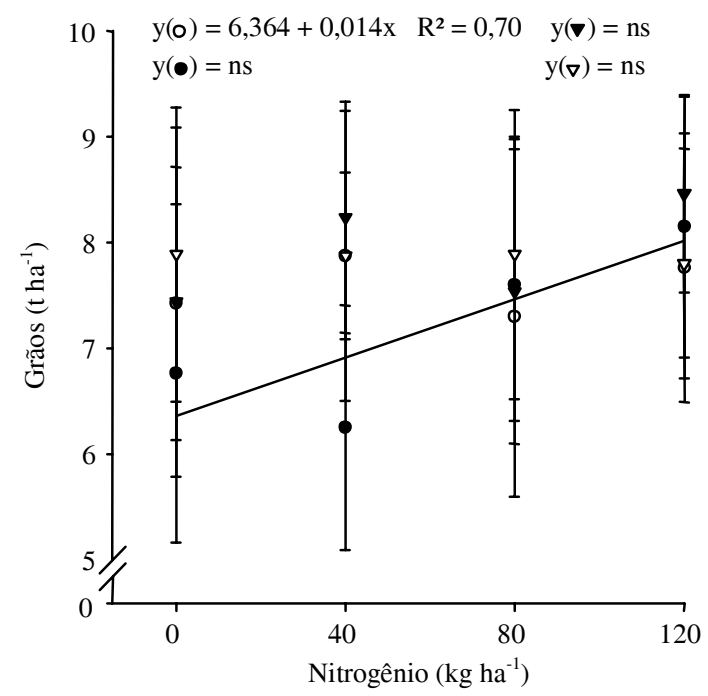

Figura 2. Rendimento de grãos de arroz irrigado em razão do nível de nitrogênio aplicado, sob quatro densidades de semeadura (50:๑ ; 100:0; $150: \boldsymbol{\nabla}$ e $\left.200: \nabla \mathrm{kg} \mathrm{ha}^{-1}\right)$, na média de duas cultivares (BR-IRGA 410 e IRGA 417). Barra vertical em cada ponto representa o desvio-padrão da média. Cachoeirinha, RS, 1999/2000. tos pelas equações $\mathrm{y}=398,5+0,84 \mathrm{x}\left(\mathrm{R}^{2}=0,84\right)$, $y=433,5+0,753 x\left(R^{2}=0,65\right), y=373,375+0,901 x$ $\left(\mathrm{R}^{2}=0,98\right)$ e y $=340+1,633 \mathrm{x}\left(\mathrm{R}^{2}=0,91\right)$, respectivamente, nos níveis de $0,40,80$ e $120 \mathrm{~kg} \mathrm{ha}^{-1}$ de $\mathrm{N}$. Na menor densidade de semeadura, o número de panículas da cultivar BR-IRGA 410 aumentou linearmente e o da IRGA 417 reduziu linearmente com incremento do nível de $\mathrm{N}$ no segundo ano. Por sua vez, na densidade de $150 \mathrm{~kg} \mathrm{ha}^{-1}$, o número de panículas reduziu-se com incremento de zero para $40 \mathrm{~kg} \mathrm{ha}^{-1}$ de $\mathrm{N}$ e aumentou a partir do nível de $80 \mathrm{~kg}^{-1}$ de $\mathrm{N}$ na cultivar IRGA 417 . Estas três regressões são descritas, respectivamente, pelas equações $\mathrm{y}=365,475+0,728 \mathrm{x}\left(\mathrm{R}^{2}=0,96\right)$, $\mathrm{y}=479,925-0,652 \mathrm{x} \quad\left(\mathrm{R}^{2}=0,56\right) \quad \mathrm{e}$ $y=549,913-2,512 x+0,0255 x^{2}\left(R^{2}=0,95\right)$.

Em relação ao número de grãos formados por panícula, foram significativos os efeitos simples de densidade de semeadura, de nível de $\mathrm{N}$ e de cultivar no ano agrícola de 1998/1999. Com incremento da densidade de semeadura, esta variável diminuiu de forma quadrática (Figura 3) e aumentou linearmente com incremento do nível de N (Figura 4). A cultivar BR-IRGA 410 apresentou número de grãos formados por panícula $17 \%$ maior (75) em relação à IRGA 417 (64). No segundo ano agrícola, foram significativos os efeitos simples de densidade de semeadura e de cultivar para esta característica. O número de grãos formados por panícula reduziu de forma linear com incremento da densidade de semeadura (Figura 5) e foi $11 \%$ maior na cultivar BR-IRGA 410 (71) em relação à IRGA 417 (64).

Quanto ao peso de 1.000 grãos, ocorreu interação simples de cultivar e nível de $\mathrm{N}$ no primeiro ano agrícola. A cultivar BR-IRGA 410 aumentou de forma quadrática com incremento da adubação nitrogenada $\left(y=27,13+0,017 x-0,0002 x^{2}, R^{2}=0,98\right)$, enquanto

Tabela 1. Rendimento de grãos $\left(\mathrm{t} \mathrm{ha}^{-1}\right)$ de duas cultivares de arroz irrigado em quatro densidades de semeadura, na média de quatro níveis de nitrogênio $\left(0,40,80\right.$ e $\left.120 \mathrm{~kg} \mathrm{ha}^{-1}\right)$, em dois anos agrícolas ${ }^{(1)}$.

\begin{tabular}{cccccc}
\hline $\begin{array}{c}\text { Densidade de } \\
\text { semeadura } \\
\left(\mathrm{kg} \mathrm{ha}^{-1}\right)\end{array}$ & BR-IRGA 410 & IRGA 417 & & \multicolumn{2}{c}{ 1999/2000 } \\
\cline { 2 - 3 } \cline { 5 - 6 } & & & & & \\
\hline 50 & 7,6 & 6,7 & & 7,9 & IRGA 417 \\
100 & 7,9 & 6,8 & & 8,2 & 7,5 \\
150 & 8,0 & 6,6 & & 8,2 & 7,7 \\
200 & 8,0 & 7,1 & & 8,5 & 7,2 \\
\hline
\end{tabular}

(1) $\mathrm{O}$ efeito da densidade de semeadura não foi significativo para ambas as cultivares e nos dois anos agrícolas, pelo teste $\mathrm{F}$ a $5 \%$ de probabilidade. 


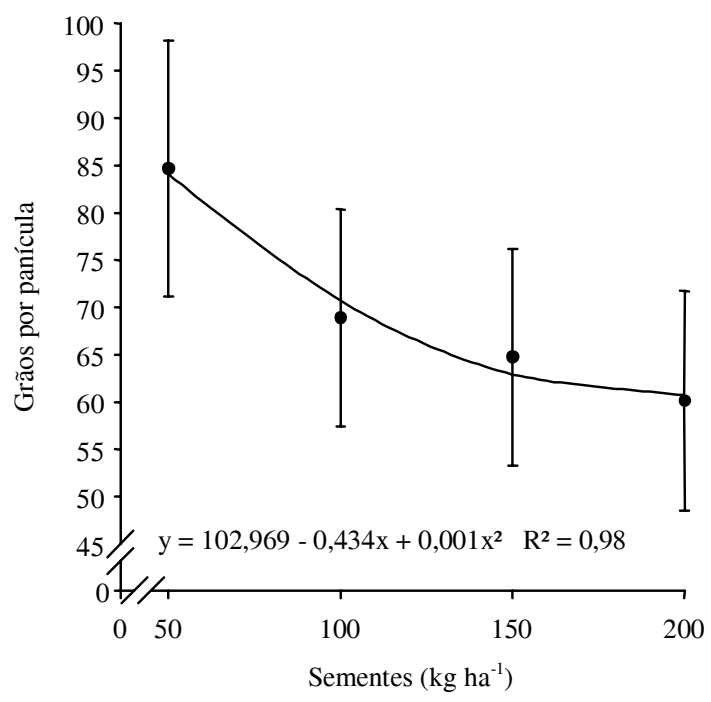

Figura 3. Número de grãos formados por panícula de arroz irrigado em razão da densidade de semeadura, na média de duas cultivares (BR-IRGA 410 e IRGA 417) e de quatro níveis de nitrogênio aplicado $\left(0,40,80\right.$ e $\left.120 \mathrm{~kg} \mathrm{ha}^{-1}\right)$. Barra vertical em cada ponto representa o desvio-padrão da média. Cachoeirinha, RS, 1998/1999.

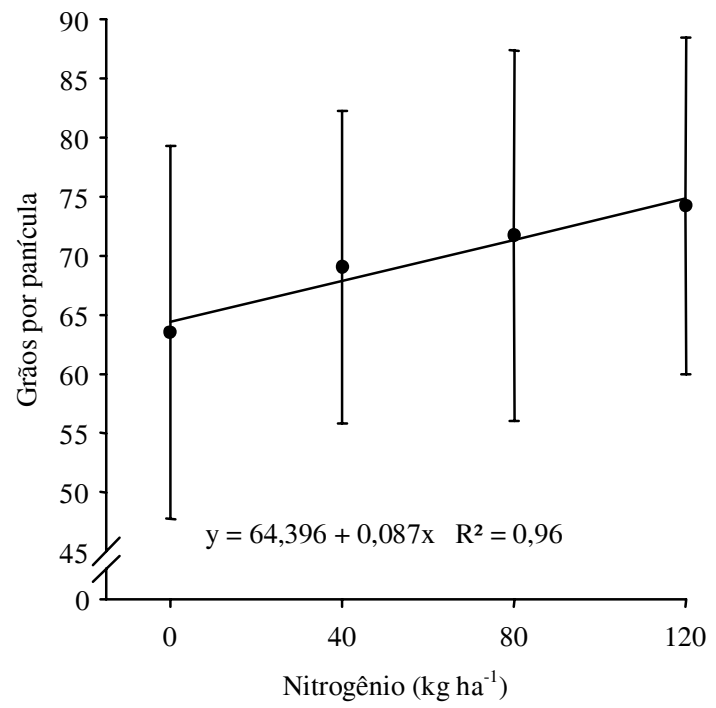

Figura 4. Número de grãos formados por panícula de arroz irrigado em razão de nível de nitrogênio aplicado, na média de duas cultivares (BR-IRGA 410 e IRGA 417) e de quatro densidades de semeadura $(50,100,150$ e $\left.200 \mathrm{~kg} \mathrm{ha}^{-1}\right)$. Barra vertical em cada ponto representa o desvio-padrão da média. Cachoeirinha, RS, 1998/1999. para a IRGA 417 não houve regressão significativa. No segundo ano agrícola, foram significativos os efeitos simples de densidade de semeadura e de cultivar. O peso de 1.000 grãos aumentou de forma quadrática com incremento da densidade de semeadura $\left(y=26,305+0,013 \mathrm{x}-0,00005 \mathrm{x}^{2}, \mathrm{R}^{2}=0,99\right)$, sendo $6 \%$ maior $(27,7 \mathrm{~g})$ na cultivar BR-IRGA 410 em relação à cultivar IRGA 417 (26,2 g).

O rendimento de grãos das duas cultivares não variou na faixa de densidade de 50 a $200 \mathrm{~kg} \mathrm{ha}^{-1}$ de sementes (Tabela 1), por causa dos aumentos do número de panículas $\mathrm{m}^{-2}$ e do peso de 1.000 grãos em resposta ao incremento da densidade de semeadura terem sido contrabalançados pela redução do número de grãos formados por panícula (Figuras 3 e 5). Esta compensação pode explicar por que em vários trabalhos não foram constatadas diferenças significativas no rendimento de grãos com aumento da densidade de semeadura, dentro de uma determinada faixa de valores (Ghobrial, 1983; Jones \& Snyder, 1987; Pedroso, 1987; Gravois \& Helms, 1992).

A ausência de resposta do rendimento de grãos à variação da densidade de semeadura foi obtida em

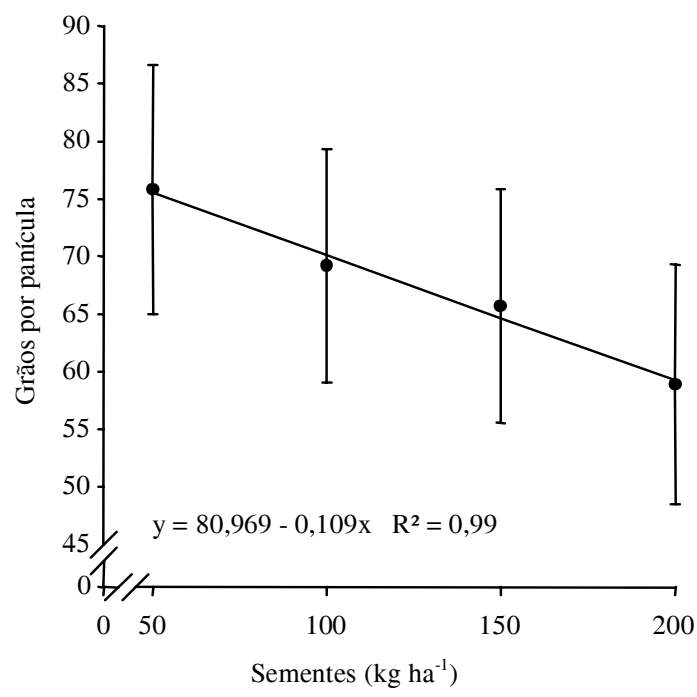

Figura 5. Número de grãos formados por panícula de arroz irrigado em razão de densidade de semeadura, na média de duas cultivares (BR-IRGA 410 e IRGA 417) e de quatro níveis de nitrogênio aplicado $\left(0,40,80\right.$ e $\left.120 \mathrm{~kg} \mathrm{ha}^{-1}\right)$. Barra vertical em cada ponto representa o desvio-padrão da média. Cachoeirinha, RS, 1999/2000. 
condições em que houve adequado controle de plantas daninhas. No entanto, quando ocorre alta infestação de plantas invasoras, principalmente de arroz vermelho, ocorre também resposta do arroz à densidade de plantas (Menezes \& Silva, 1998).

As variações nos componentes do rendimento em razão da densidade de plantas devem-se à capacidade de adaptação apresentada pelas plantas de arroz, que está associada ao maior número de panículas por unidade de área, quando cultivada em maiores populações de plantas, e a maior produção de grãos por panícula, quando em populações menores (Souza et al., 1993). A capacidade de adaptação das plantas às diferentes densidades de semeadura e espaçamentos entre linhas é influenciada pela espécie e pelo genótipo (Pereira, 1989; Loomis \& Connor, 1992). Entre os fatores que conferem maior adaptação ao arroz, o afilhamento é o mais expressivo, por capacitar as plantas a ocuparem rapidamente o espaço disponível (Pereira, 1989).

O aumento do rendimento de grãos das cultivares com incremento das doses de $\mathrm{N}$ ocorrido no primeiro ano (Figura 1) deveu-se, principalmente, ao aumento do número de grãos formados por panícula (Figura 4), já que o número de panículas $\mathrm{m}^{-2}$ não variou com o nível de N aplicado. Wells \& Faw (1978) e Singh \& Pillai (1996) têm atribuído o aumento do rendimento de grãos em decorrência do incremento da adubação nitrogenada ao aumento do número de grãos formados por panícula. No entanto, Ghobrial (1983) e Reddy et al. (1986) também consideraram o aumento do número de panículas por unidade de área como um fator determinante do aumento do rendimento de grãos de arroz com incremento do nível de $\mathrm{N}$ aplicado.

No segundo ano agrícola, apenas na densidade de semeadura de $50 \mathrm{~kg} \mathrm{ha}^{-1}$ houve aumento no rendimento de grãos com incremento do nível de $\mathrm{N}$ aplicado (Figura 2). Em relação à cultivar BR-IRGA 410, o número de panículas $\mathrm{m}^{-2}$ também aumentou somente na menor densidade de plantas. Desta forma, no ano em que a resposta ao $\mathrm{N}$ foi menor, quando houve resposta, esta só ocorreu na densidade mais baixa de semeadura. Resultados semelhantes foram obtidos por Wells \& Faw (1978).

Quanto à eficiência de uso do N (EUN) na parte aérea das plantas, no estádio de diferenciação do primórdio da panícula (DPP), houve interação simples entre densidade de semeadura e nível de $\mathrm{N}$ na primeira estação de crescimento. Assim, com incremento do nível de $\mathrm{N}$ aplicado, a redução na EUN foi de forma quadrática nas densidades de semeadura de 50 e $200 \mathrm{~kg} \mathrm{ha}^{-1} \mathrm{e}$, de forma linear, nas densidades de 100 e $150 \mathrm{~kg} \mathrm{ha}^{-1}$ (Figura 6). No segundo ano agrícola, foi significativo apenas o efeito simples de cultivar para esta característica. A cultivar BR-IRGA 410 apresentou EUN 10\% maior do que a IRGA 417. Quanto à EUN na parte aérea das plantas no florescimento, houve apenas efeito simples de cultivar, com a BR-IRGA 410 apresentando EUN 12\% maior do que a IRGA 417. Em relação à EUN nos grãos, foram significativos os efeitos simples do nível de $\mathrm{N}$ e de cultivar, isto é, a EUN nos grãos diminuiu linearmente com incremento do nível de $\mathrm{N}$ aplicado (Figura 7) e foi $4 \%$ maior na cultivar BR-IRGA 410 em relação à IRGA 417.

Independentemente da densidade de semeadura, a EUN na parte aérea da planta de arroz, avaliada na

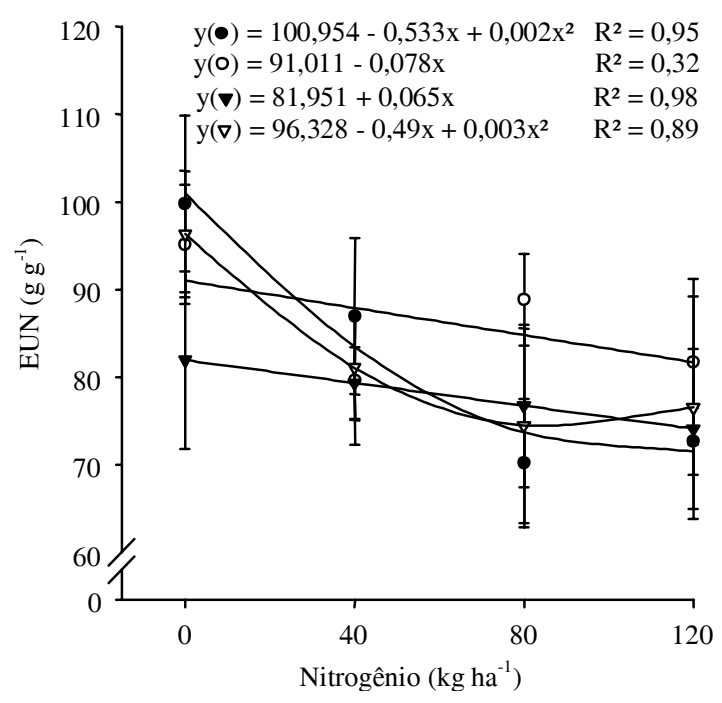

Figura 6. Eficiência de uso do nitrogênio (EUN) na matéria seca (MS) da parte aérea das plantas de arroz irrigado na diferenciação do primórdio da panícula em razão de nível de nitrogênio aplicado, sob quatro densidades de semeadura (50: ; 100:O; 150: $\nabla$ e 200: $\left.\nabla \mathrm{kg} \mathrm{ha}^{-1}\right)$, na média de duas cultivares (BR-IRGA 410 e IRGA 417). Barra vertical em cada ponto representa o desvio-padrão da média. Cachoeirinha, RS, 1998/1999. 
diferenciação do primórdio da panícula, diminuiu no primeiro ano com incremento do nível de $\mathrm{N}$ aplicado (Figura 6). O mesmo ocorreu com a EUN nos grãos, avaliada apenas no segundo ano (Figura 7). Em trabalhos realizados com arroz (Borrell et al., 1998), trigo e cevada (Sieling et al., 1998), milheto (Maman et al., 1999) e sorgo (Traore \& Maranville, 1999), também constatou-se redução na eficiência de uso do $\mathrm{N}$ com incremento da adubação nitrogenada. Este fato pode estar associado ao aumento de perdas de $\mathrm{N}$ por volatilização e percolação, entre outras formas em decorrência da maior quantidade aplicada (Raun \& Johnson, 1999). Neste sentido, De Datta et al. (1991) concluíram que a maior perda do $\mathrm{N}$ aplicado na forma de uréia em lavouras de arroz ocorre por meio do processo de volatilização que intensifica-se com o aumento do $\mathrm{pH}$, da temperatura da água e da velocidade do vento.

$\mathrm{O}$ arroz responde à adubação nitrogenada até determinado nível de $\mathrm{N}$ aplicado, como foi observado em relação à cultivar BR-IRGA 410 no primeiro ano (Figura 1). Com incremento da adubação

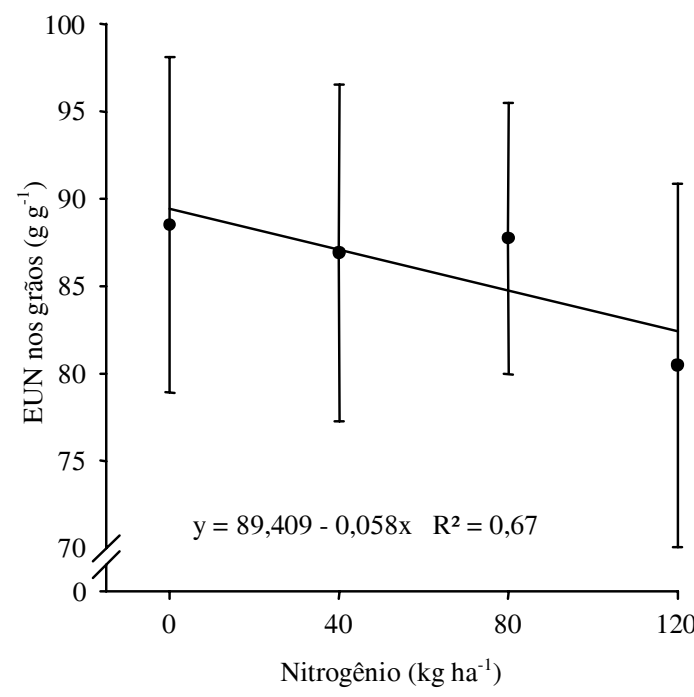

Figura 7. Eficiência de uso do nitrogênio (EUN) nos grãos de arroz irrigado em razão de nível de nitrogênio aplicado, na média de duas cultivares (BR-IRGA 410 e IRGA 417) e de quatro densidades de semeadura $(50,100,150 \mathrm{e}$ $200 \mathrm{~kg} \mathrm{ha}^{-1}$ ). Barra vertical em cada ponto representa o desvio-padrão da média. Cachoeirinha, RS, 1999/2000. nitrogenada, a absorção e o aproveitamento do $\mathrm{N}$ pelas plantas diminuem (Arima, 1995). Por sua vez, este comportamento não foi evidenciado pela cultivar IRGA 417 no primeiro ano, em que o rendimento de grãos aumentou linearmente em relação à adubação nitrogenada (Figura 1), indicando que ela necessitaria de maior quantidade de $\mathrm{N}$ para atingir a produção máxima. A cultivar BR-IRGA 410 apresentou maior EUN do que a IRGA 417, tanto na parte aérea das plantas como nos grãos. No segundo ano agrícola, a cultivar BR-IRGA 410 produziu mais massa seca e mais grãos para cada grama de $\mathrm{N}$ acumulado em comparação à IRGA 417. A produção e a distribuição de fotoassimilados estão relacionadas com o suprimento de $\mathrm{N}$ e com a cultivar, e as cultivares que respondem mais à adubação nitrogenada, em geral, são mais eficientes em fotossíntese (Osada, 1995).

\section{Conclusões}

1. O rendimento de grãos de cultivares de arroz irrigado em relação à adubação nitrogenada é influenciado apenas na densidade de $50 \mathrm{~kg} \mathrm{ha}^{-1}$.

2. O rendimento de grãos não variou na faixa de densidade de 50 a $200 \mathrm{~kg} \mathrm{ha}^{-1}$ de sementes, o que mostra a adaptação das plantas de arroz a essa variável.

3. A eficiência de uso do $\mathrm{N}$ é maior na cultivar BR-IRGA 410 do que na IRGA 417 e decresce com o incremento da adubação nitrogenada, independentemente da densidade de semeadura.

\section{Referências}

ARIMA, Y. Uptake and accumulation of nitrogen. In: MATSUO, T.; KUMAZAWA, K.; ISHII, R.; ISHIHARA, K.; HIRATA, H. (Ed.). Science of the rice plant. Tokyo: Food and Agriculture Policy Research Center, 1995. v. 2, p. 327-343.

BALIGAR, V. C.; DUNCAN, R. R.; FAGERIA, N. K. Soil-plant interaction on nutrient use efficiency in plants: an overview. In: BALIGAR, V. C.; DUNCAN, R. R. (Ed.). Crops as enhancers of nutrient use. San Diego: Academic, 1990. p. 351-373.

BARBOSA FILHO, M. P. Nutrição e adubação do arroz: sequeiro e irrigado. Piracicaba: Potafos, 1987. 129 p. (Boletim Técnico, 9). 
BORRELL, A. K.; GARSIDE, A. L.; FUKAI, S.; REID, D. J. Season, nitrogen rate, and plant type affect nitrogen uptake and nitrogen use efficiency in rice. Australian Journal of Agricultural Research, Collingwood, v. 49, n. 5, p. 829-843, 1998.

BRASIL. Ministério da Agricultura. Departamento Nacional de Pesquisa Agropecuária. Divisão de Pesquisa Pedológica. Levantamento de reconhecimento dos solos do estado do Rio Grande do Sul. Recife, 1973. 431 p. (Boletim Técnico, 30).

BREDEMEIER, C.; MUNDSTOCK, C. M. Regulação da absorção e assimilação do nitrogênio nas plantas. Ciência Rural, Santa Maria, v. 30, n. 2, p. 365-372, 2000.

DE DATTA, S. K.; BURESH, R. J.; SAMSON, M. I.; OBCEMEA, W. N.; REAL, J. G. Direct measurement of ammonia and denitrification fluxes from urea applied to rice. Soil Science Society of America Journal, Madison, v. 55, n. 2, p. 543-548, 1991.

EMBRAPA. Centro de Pesquisa Agropecuária de Clima Temperado (Pelotas, RS). Arroz irrigado: recomendações técnicas da pesquisa para o Sul do Brasil. Pelotas: Embrapa-CPACT/Instituto Rio-Grandense do Arroz/ Epagri, 1999. 124 p. (Embrapa-CPACT. Documentos, 57).

EMBRAPA. Centro Nacional de Pesquisa de Solos (Rio de Janeiro, RJ). Sistema brasileiro de classificação de solos. Brasília: Embrapa-SPI/Embrapa-CNPS, 1999. $412 \mathrm{p}$.

EPAGRI. Estação Experimental de Itajaí. Arroz irrigado: recomendações técnicas da pesquisa para o Sul do Brasil. 4. ed. Itajaí, 1997. 80 p.

GHOBRIAL, G. I. Response of irrigated dry seeded rice to nitrogen level, interrow spacing, and seeding rate in a semiarid environment. International Rice Research Newsletter, Manila, v. 8, n. 4, p. 27-28, 1983.

GRAVOIS, K. A.; HELMS, R. S. Path analysis of rice yield and yield components as affected by seeding rate. Agronomy Journal, Madison, v. 84, n. 1, p. 1-4, 1992.

INFELD, J. A.; ZONTA, E. P. Densidade na BR-IRGA 410. In: REUNIÃO DA CULTURA DO ARROZ IRRIGADO, 13., 1984, Balneário Camboriú. Anais... Florianópolis: Empasc, 1984. p. 247-251.

INSTITUTO DE PESQUISA AGROPECUÁRIA (Porto Alegre, RS). Guaíba. In: Observações meteorológicas no Estado do Rio Grande do Sul. Porto Alegre, 1979. p. 55-66. (Boletim Técnico, 3).

INTERNATIONAL RICE RESEARCH INSTITUTE (Los Baños, Filipinas). Standard evaluation system for rice. 4. ed. Manila, 1996. 58 p.

JONES, D. B.; SNYDER, G. H. Seeding rate and row spacing effects on yield and yield components of drillseeded rice. Agronomy Journal, Madison, v. 79, n. 4, p. 623-626, 1987.

LOOMIS, R. S.; CONNOR, D. J. Crop ecology: productivity and management in agricultural systems. Cambridge, Inglaterra: Cambridge University Press, 1992. p. $32-59$.

LOPES, S. I. G.; LOPES, M. S.; MACEDO, V. R. M. Curva de resposta à aplicação de nitrogênio para quatro genótipos de arroz irrigado. Lavoura Arrozeira, Porto Alegre, v. 49, n. 425, p. 3-6, 1996.

MAMAN, N.; MASON, S. C.; GALUSHA, T.; CLEGG, M. D. Hybrid and nitrogen influence on pearl millet production in Nebraska: yield, growth, and nitrogen uptake, and nitrogen use efficiency. Agronomy Journal, Madison, v. 91 , n. 5, p. 737-743, 1999.

MENEZES, V. G.; SILVA, P. R. F. da. Manejo de arroz vermelho através do tipo e arranjo de plantas em arroz irrigado. Planta Daninha, Botucatu, v. 16, n. 1, p. 45-58, 1998.

OSADA, A. Photosynthesis and respiration in relation to nitrogen responsiveness. In: MATSUO, T.; KUMAZAWA, K.; ISHII, R.; ISHIHARA, K.; HIRATA, H. (Ed.). Science of the rice plant. Tokyo: Food and Agriculture Policy Research Center, 1995. v. 2, p. 696-703.

PEDROSO, B. A. Densidade e espaçamento entre linhas para arroz (Oryza sativa L.) irrigado. Lavoura Arrozeira, Porto Alegre, v. 40, n. 370, p. 6-10, 55-59, 1987.

PEDROSO, B. A.; REGINATTO, M. da P. V. Densidade de semeadura em arroz irrigado. In: REUNIÃO DA CULTURA DO ARROZ IRRIGADO, 11., 1981, Pelotas. Anais... Pelotas: Embrapa-Uepae Pelotas, 1981. p. 141-145.

PEREIRA, A. R. Competição intra-específica entre plantas cultivadas. Agronômico, Campinas, v. 41, n. 1, p. 5-11, 1989. 
RAIJ, B. V. Fertilidade do solo e adubação. Piracicaba: Ceres/Potafos, 1991. 343 p.

RAUN, W. R.; JOHNSON, G. V. Improving nitrogen use efficiency for cereal production. Agronomy Journal, Madison, v. 91, n. 3, p. 357-363, 1999.

REDDY, M. D.; GHOSH, B. C.; PANDA, M. M. Effect of seed rate and application of $\mathrm{N}$ fertilizer on grain yield and $\mathrm{N}$ uptake of rice under intermediate deepwater conditions (15-50 cm). Journal of Agricultural Science, Cambridge, Inglaterra, v. 107, n. 1, p. 61-66, 1986.

SIELING, K.; SCHRÖDER, H.; FINCK, M.; HANUS, $\mathrm{H}$. Yield, $\mathrm{N}$ uptake, and apparent N-use efficiency of winter wheat and winter barley grown in different cropping systems. Journal of Agricultural Science, Cambridge, Inglaterra, v. 131, n. 4, p. 375-387, 1998.

SILVA, P. R. F. da; MENEZES, V. G.; MARIOT, C. H. P.; CARMONA, R. C.; REZERA, F. Resposta de duas cultivares de arroz irrigado a três densidades de semeadura e a três espaçamentos entre linhas. In: REUNIÃO DA CULTURA DO ARROZ IRRIGADO, 21., 1995, Porto Alegre. Anais... Porto Alegre: Instituto Rio-Grandense do Arroz, 1995. p. 153-154.
SINGH, S. P.; PILLAI, K. G. Response of scented rice varieties to nitrogen. Oryza, Cuttack, v. 33, n. 3, p. 193-195, 1996

SOUZA, R. O.; MARTINS, J. F. da S.; GOMES, A. da S.; SILVA, L. S. Densidade de semeadura e espaçamento entre linhas para o arroz irrigado cultivado no sistema de plantio direto. In: REUNIÃO DA CULTURA DO ARROZ IRRIGADO, 20., 1993, Pelotas. Anais... Pelotas: Embrapa-CPACT, 1993. p. 139-141. (Documentos, 1).

TEDESCO, M. J.; GIANELLO, C.; BISSANI, C. A.; BOHNEN, H.; VOLKWEISS, S. J. Análise de solo, plantas e outros materiais. 2. ed. Porto Alegre: UFRGS, 1995. $174 \mathrm{p}$.

TRAORE, A.; MARANVILLE, J. W. Nitrate reductase activity of diverse grain sorghum genotypes and its relationship to nitrogen use efficiency. Agronomy Journal, Madison, v. 91, n. 5, p. 863-869, 1999.

WELLS, B. R.; FAW, W. F. Short-statured rice response to seeding and $\mathrm{N}$ rates. Agronomy Journal, Madison, v. 70, n. 3, p. 477-480, 1978. 